\title{
Caracterização parcial do extrato bruto e pré-purificado de Lipase de Yarrowia lipolytica
}

\section{Tamires Carvalho dos Santos ${ }^{1}$, Priscilla Vanessa Finotelli ${ }^{2}$ e Priscilla Filomena Fonseca Amaral $^{1}$}

\author{
${ }^{1}$ Universidade Federal do Rio de Janeiro - Departamento de Engenharia Bioquímica \\ CEP 21941-909 Rio de Janeiro - RJ - E-mail: tcsantos@ufrj.br \\ ${ }^{2}$ Universidade Federal do Rio de Janeiro -Departamento de Produtos Naturais e Alimentos \\ 21941-590 Rio de Janeiro - RJ
}

\begin{abstract}
RESUMO
As lipases são serina hidrolases definidas como triacilglicerol acilhidrolases que catalisam naturalmente a hidrólise da ligação éster de tri-, di- e mono -gliceróis de ácidos graxos de cadeia longa em ácidos graxos e glicerol. Em condições termodinamicamente favoráveis, esses biocatalisadores são capazes de catalisar reações de síntese, tais como esterificação ou transesterificação de grande interesse industrial. A produção da lipase realizada em biorreator de bancada de $3 \mathrm{~L}$ gerou, após $24 \mathrm{~h}$ de cultivo, um extrato enzimático bruto (EEB) com atividade hidrolítica de $61,4 \mathrm{U} / \mathrm{mL}$ e atividade proteolítica foi de $0,175 \mathrm{U} / \mathrm{mL}$, com a purificação 0 a atividade enzimática da lipase foi reduzida para $43,29 \mathrm{U} / \mathrm{mL}$, já para a protease a atividade foi reduzida, quantificada a 0,035 U/mL. Com a caracterização parcial é possível estabelecer, que a enzima apresenta grande possibilidade de inserção industrial tanto em seu estado bruto quanto no purificado.
\end{abstract}

Palavras-chave: biorreator, temperatura ótima, pH ótimo.

\section{INTRODUÇÃO}

As lipases (glicerol éster hidrolases, E.C.3.1.1.3) são enzimas hidrolíticas em seu ambiente natural. Estas possuem a função de catalisar a hidrólise de triacilgliceróis (ZAREVUCKA et al., 1995). Elas representam um grupo de biocatalisadores acessíveis, que em geral, são flexíveis quanto à sua especificidade. São as enzimas mais empregadas tanto em nível industrial (indústria alimentícia, de cosméticos e perfumes, biomédica, pesticidas, detergentes, entre outras) como acadêmico (BREUER et al., 2004).

Além disso, as lipases usualmente atuam sobre substratos não naturais. A maioria dos custos de produção para um produto biológico simples reside na estratégia de purificação. Existe uma grande necessidade de se estabelecer técnicas de biosseparação eficientes, efetivas e econômicas em larga escala, que permitam atingir elevado grau pureza e rendimento de recuperação, mantendo a atividade biológica da molécula. Neste estudo, foi realizada a produção de lipase extracelular da levedura Yarrowia lipolytica e caracterização e purificação parcial da enzima em relação à força iônica e temperatura.

\section{Micro-organismo utilizado}

\section{MATERIAL E MÉTODOS}

A levedura empregada no presente trabalho foi uma cepa selvagem de Yarrowia lipolytica (IMUFRJ 50682) selecionada de um estuário da Baía de Guanabara no Rio de Janeiro, Brasil (HAGLER e MENDONÇA-HAGLER, 1981) e identificada pelo Instituto de Microbiologia do Centro de Ciências da Saúde da Universidade Federal do Rio de Janeiro. As células foram conservadas a $4^{\circ} \mathrm{C}$ após 24 horas 


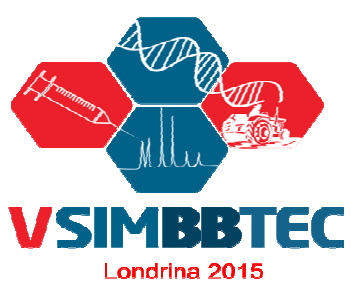

\section{SIMPÓSIO DE BIOQUÍMICA E BIOTECNOLOGIA}

05 a 07 de agosto de 2015, Londrina - PR

de crescimento em tubos de ensaio com meio YPD ("Yeast Extract, Peptone, Dextrose") contendo (em $\mathrm{m} / \mathrm{v}$ ): extrato de lêvedo $1 \%$, peptona $2 \%$, glicose $2 \%$ e Agar-agar $2 \%$ (AMARAL, 2007).

A partir dos tubos contendo as células preservadas em meio sólido YPD (descrito no item 2.1) inoculava-se, de forma estéril com uma alça de platina, $200 \mathrm{~mL}$ de meio de cultivo YPD em Erlenmeyers de $500 \mathrm{~mL}$. Após cerca de 70 horas em um incubador rotatório a $29^{\circ} \mathrm{C}, 160 \mathrm{rpm}$, as células foram centrifugadas de forma estéril a $3.000 \mathrm{~g}$ por 10 minutos e ressuspensas em $10 \mathrm{~mL}$ de meio de cultivo, servindo de inoculo dos experimentos descritos nos itens posteriores. $O$ volume centrifugado desse pré-inóculo era suficiente para se obter uma concentração inicial de células de, aproximadamente, 1,0 \pm 0,1 mg p.s.cel/mL nos meios de cultivo (AMARAL, 2007).

\section{Processo fermentativo para otenção da enzima}

A produção de lipase ocorreu em reator Microferm de New Brunswick MF-114, com volume efetivo para de 3 litros, em condições anteriormente otimizadas por Amaral (2007). A fermentação foi conduzida com, agitadores tipo Rushton, aeração a 1,5 L. $\mathrm{min}^{-1}$, com agitação mecânica, velocidade de agitação $650 \mathrm{rpm}$ e temperatura mantida a $28^{\circ} \mathrm{C}$. Após o período ótimo reacional $(24 \mathrm{~h})$, o meio foi coletado e centrifugado a temperatura ambiente durante $10 \mathrm{~min}$ a $2016 \mathrm{~g}$. $\mathrm{O}$ sobrenadante foi utilizado como extrato enzimático, uma vez que a Yarrowia lipolytica produz lipase extracelular (KORDEL et al., 1991).

\section{Métodos analíticos}

A atividade lipolítica foi determinada por titulação dos ácidos graxos gerados na reação de hidrólise do óleo de oliva segundo a metodologia descrita por Macedo e colaboradores (1997), utilizando uma emulsão contendo $5 \mathrm{~mL}$ de azeite de oliva e goma arábica a $7 \%, 2 \mathrm{~mL}$ de tampão fosfato de sódio $\mathrm{pH} 7(10 \mathrm{mM})$ e $1 \mathrm{~mL}$ de extrato enzimático. Uma unidade de atividade de lipase foi definida como a quantidade de enzima que libera um $\mu \mathrm{mol}$ de ácido graxo por minuto.

A concentração de glicose presente do meio de cultivo foi medida pelo método da glicose oxidase utilizando um kit enzimático para medida colorimétrica de glicose (HUMAN GmbH - Germany ${ }^{\circledR}$ ), 0 crescimento celular foi acompanhado através de medidas de absorvância em espectrofotômetro (SHIMADZU - UV-2450) a $570 \mathrm{~nm}$ e esses valores foram convertidos para $\mathrm{mg}$ p.s. cél/mL utilizandose o fator de conversão obtido pela curva de peso seco. A medida de atividade de protease foi realizada segundo PINTO (1998). Para determinar o efeito da massa molar do tampão a atividade lipolítica (força iônica) do extrato bruto variando-se o pH do meio à concentração do tampão fosfato pH $7(10 \mathrm{mM}$ e $100 \mathrm{mM})$. O efeito da temperatura na atividade da enzima foi avaliado variando a temperatura reacional de 20 a $100{ }^{\circ} \mathrm{C}$, já o efeito do $\mathrm{pH}$ foi avaliado na faixa de 3 a 9 , segundo Santos et al. (2013).

\section{Purificação parcial}

Para a purificação parcial do extrato bruto enzimático, foram adicionados $4 \%(\mathrm{~m} / \mathrm{v})$ de caulim industrial, com homogeneização de 3 minutos em agitador tipo vortex. Após 15min de repouso, em temperatura ambiente, foi filtrado em papel filtro Whatmam $\mathrm{n}^{0} 1$, a vácuo. As proteínas do filtrado foram concentradas com 3 vezes o valor do volume inicial de acetona a frio, centrifugadas a $4000 \mathrm{~g} \mathrm{e}$ o precipitado ressuspenso em $10 \%$ do volume inicial de filtrado (GOULART et al., 2009).

\section{RESULTADOS E DISCUSSÃO}

A figura 1 apresenta a cinética de consumo de glicose e de crescimento celular durante a produção de lipase. No crescimento de $Y$. lipolytica em meio contendo glicose como fonte de carbono, foi observado um decaimento na concentração de glicose ao decorrer do tempo, até sua exaustão em menos de $24 \mathrm{~h}$. $\mathrm{O}$ crescimento celular $(\Delta \mathrm{X})$ em $24 \mathrm{~h}$ foi de $12 \mathrm{mg}$ de cél/mL e a taxa específica de crescimento na fase exponencial $(\mu)$ foi $0,1 \mathrm{~h}^{-1}$. Ao fim do processo (24 horas) a

Universidade Estadual de Londrina - Rodovia Celso Garcia Cid, Pr 445, Km 380 - Campus Universitário Caixa Postal 10.011 CEP 86057-970 Centro de Ciências Exatas - Departamento de Bioquímica e Biotecnologia Fone +55 


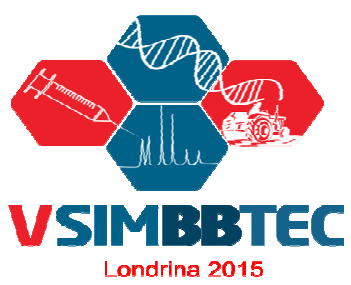

\section{SIMPÓSIO DE BIOQUÍMICA E BIOTECNOLOGIA} 05 a 07 de agosto de 2015, Londrina - PR

atividade da lipase (atividade hidrolítica sobre p-nitrofenillaurato - p-NFL) do extrato bruto livre de células atingiu $61,4 \mathrm{U} / \mathrm{mL}$ e a quantidade de proteína solúvel foi $0,315 \mathrm{mg} / \mathrm{mL}$. No mesmo extrato foi quantificada a atividade de $0,175 \mathrm{U} / \mathrm{mL}$ de protease. Com a purificação parcial realizada com acetona e caulim a atividade final da lipase do extrato concentrado foi de $43,29 \mathrm{U} / \mathrm{mL}$, com 0,431 mg/ml de proteína solúvel e protease quantificada a $0,035 \mathrm{U} / \mathrm{mL}$. O fator de purificação (F.P.) foi de apenas 0,5 . Porém, como vantagem observou-se que houve redução da atividade de protease, condição relevante para maior estabilidade da enzima de interesse.

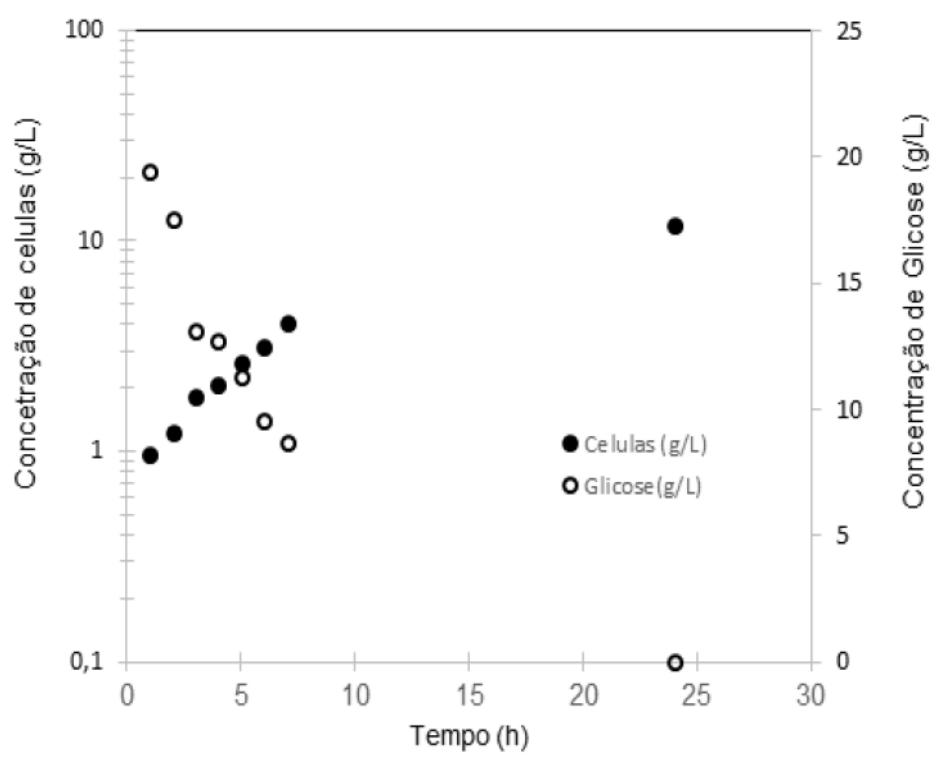

Figura 1: Cinética de crescimento celular e consumo de glicose para o cultivo de Yarrowia lipolytica em biorreator.

A figura 2 apresenta a influência da força iônica do meio, obtida com diferentes massas molares de tampão fosfato em $\mathrm{pH} 7$, na atividade da hidrolítica do extrato enzimático bruto em p-NFL. Neste ensaio foi possível observar que as melhores atividades de hidrolise do p-NFL, está numa faixa compreendida entre 40 e $60 \mathrm{mM}$. A medida de atividade de lipase é realizada em usualmente com tampão fosfato 50mM (AMARAL, 2007). Portanto, o resultado obtido no presente trabalho está de acordo com a literatura. Com base nisso, a massa molar do tampão fosfato escolhida para os demais ensaios foi $50 \mathrm{mM}$.

$\mathrm{Na}$ figura 3 são apresentados os ensaios relativos à temperatura e pH ótimos do EEB e do extrato purificado de lipase em relação à hidrólise do óleo de oliva. Observa-se perfis similares para os dois extratos, mostrando que a purificação não causou alterações significativas na enzima. A figura $3 a$ mostra que a temperatura ideal do EEB está próxima a $37^{\circ} \mathrm{C}$, porém a enzima manteve uma atividade considerável a 40 e $50^{\circ} \mathrm{C}$ com a atividade relativa quantificada em 96 e $82 \%$ respectivamente, 0 que pode indicar que a enzima apresenta tolerância a temperaturas mais elevadas. Para o extrato purificado, a atividade ótima encontra-se em uma faixa ligeiramente inferior $\left(20\right.$ a $\left.30^{\circ} \mathrm{C}\right)$, mas apresenta também atividade relativa elevada à $50^{\circ} \mathrm{C}$. Na figura $3 \mathrm{~b}$ é possível observar que a atividade da enzimática foi máxima entre os pHs 5 a 7, tanto para o EEB como para o extrato purificado, o que favorece o seu melhor desempenho em uma faixa próxima a neutralidade.

Universidade Estadual de Londrina - Rodovia Celso Garcia Cid, Pr 445, Km 380 - Campus Universitário Caixa Postal 10.011 CEP 86057-970 Centro de Ciências Exatas - Departamento de Bioquímica e Biotecnologia Fone +55 


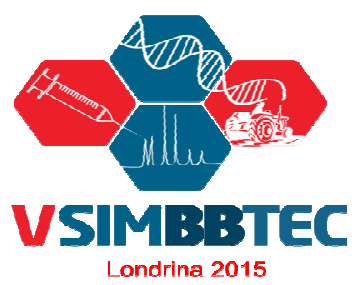

\section{SIMPÓSIO DE BIOQUÍMICA E BIOTECNOLOGIA} 05 a 07 de agosto de 2015, Londrina - PR

Londrina 2015

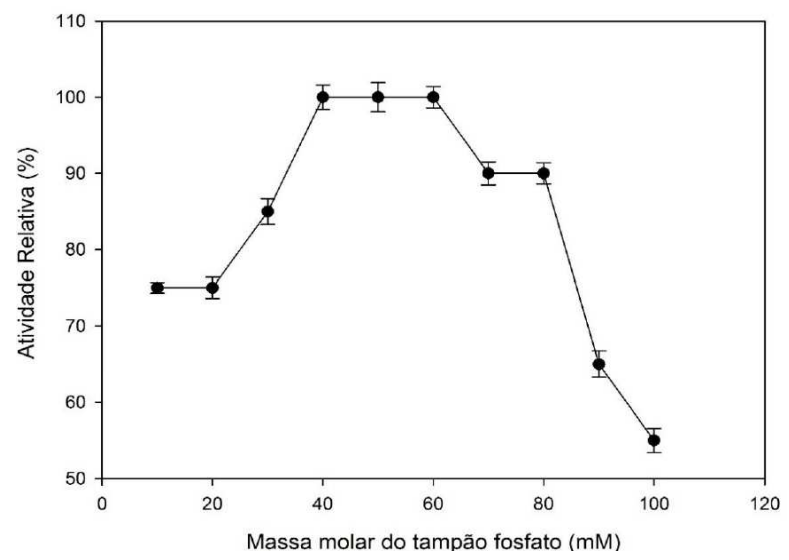

Figura 2: Influência da força iônica do meio reacional na atividade hidrolítica do extrato enzimático bruto em p-nitrofenil-laurato.
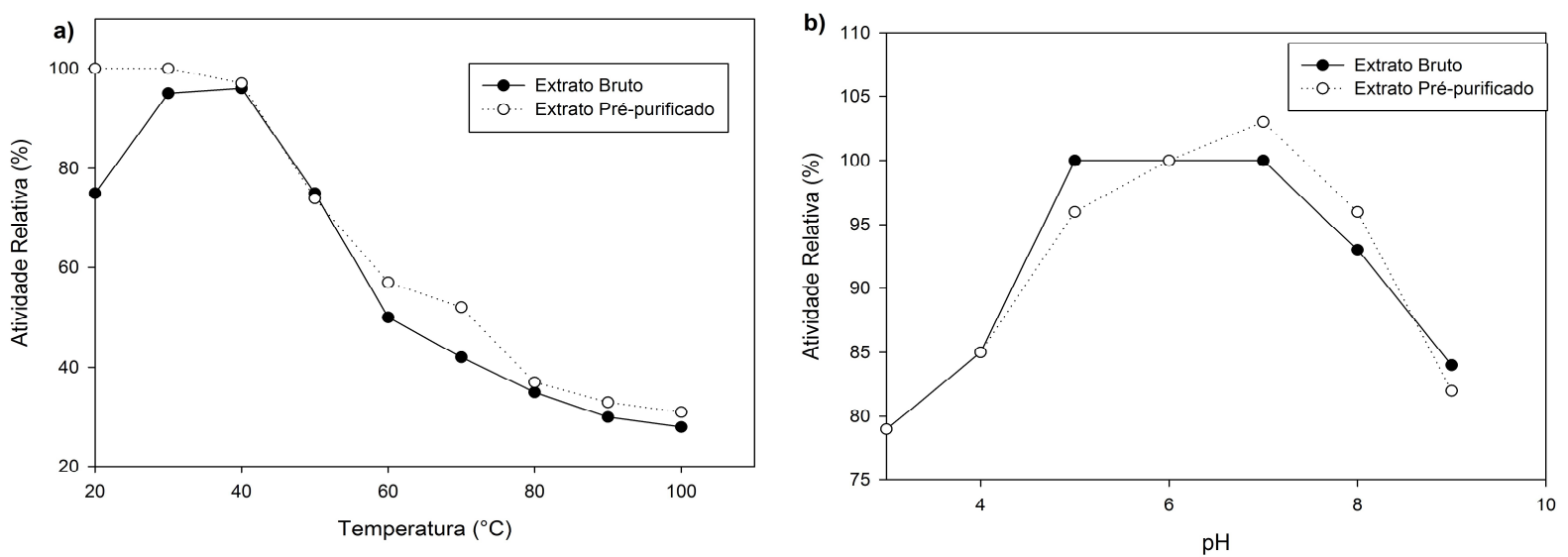

Figura 3: Caracterização parcial do extrato bruto e purificado parcialmente da lipase: a) temperatura ótima; b) pH ótimo.

\section{CONCLUSÕES}

A produção da lipase por Yarrowia lipolytica em biorreator de $3 \mathrm{~L}$ apresentou resultados de atividade elevados, comparáveis com o que a literatura reporta. O extrato bruto livre de células e sua forma purificada parcialmente, apresentam uma abrangente faixa de $\mathrm{pH}$ e temperatura.

\section{REFERÊNCIAS}

AMARAL, P. F. F. Produção de lipase de Yarrowia lipolytica em Biorreator Multifásico. 2007. 220 p.29,7 cm. Tese

(Doutorado) - Universidade Federal do Rio de Janeiro - UFRJ, Programa de Pós-Graduação em Tecnologia de Processos Químicos e Bioquímicos - EQ, 2007.

BREUER, M., DITRICH, K., HABICHER, T., HAUER, B., KESSELER, M., STURMER, R., ZELINSKI, T. Industrial methods for

the production of optically active intermediates. Angewandte Chemie International Edition, v. 43, n. 7, pg.788824, 2004.

HAGLER, A.N.; MENDONÇA-HAGLER, L. C. Yeasts from Marine and Estuarine Waters with Different Levels of Pollution in the State of Rio de Janeiro, Brazil. Applied and Environmental Microbiology, v. 41, n.1, n 173-178, 1981.

ZAREVUCKA, M.; ZALSKA, Z.; REJZEK, M.; STREINZ, L.; WIMMER, Z.; MACKOVA, M.; DEMNEROVA, K. Lipase- mediated hydrolysis and esterification. Enzyme Microbiology Technology, v. 17, n. 10, pg.866-869, 1995.

SANTOS, T. C.; FILHO, G. A.. ; OLIVEIRA, A. C. ; ROCHA, T. J. O. ; MACHADO, F. P. P. ; BONOMO, R. C. F. ; BONOMO, R. C. F. ; MOTA, K. I. A. ; FRANCO, M. . Application of response surface methodology for producing cellulolytic enzymes by solid-state fermentation from the puple mombin (Spondias purpurea L.) residue. Food Science and Biotechnology, v. 22, p. 1-7, 2013.

Universidade Estadual de Londrina - Rodovia Celso Garcia Cid, Pr 445, Km 380 - Campus Universitário Caixa Postal 10.011 CEP 86057-970 Centro de Ciências Exatas - Departamento de Bioquímica e Biotecnologia Fone +55 